FOR THE PEOPLE FOR EDVCATION FOR SCIENCE

LIBRARY

OF

THE AMERICAN MUSEUM OF NATURAL HISTORY 


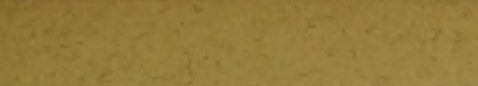






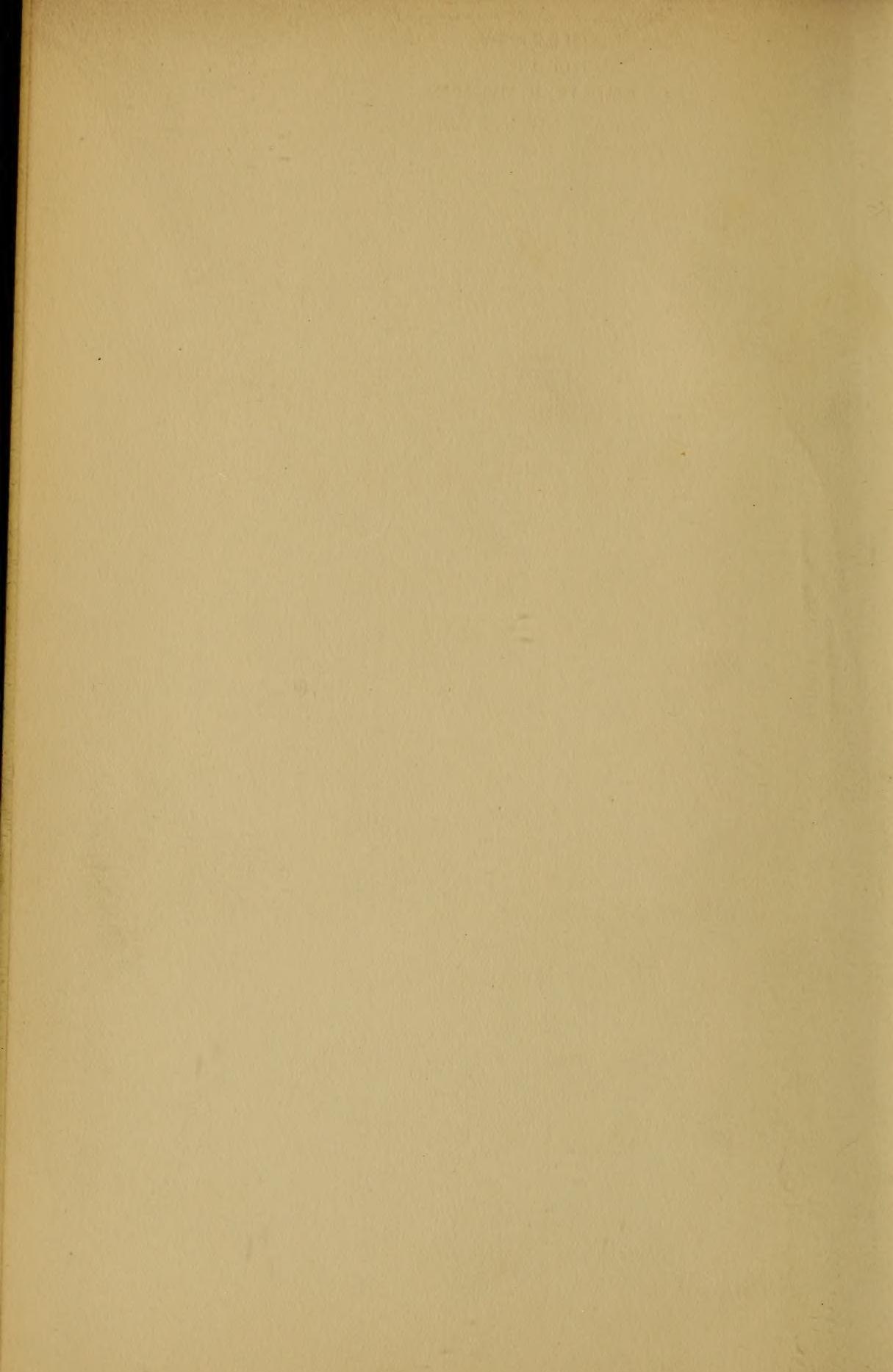


AMERICAN MUSEUM OF NATURAL HISTORY

\section{HANDBOOK OF HEALTH IN WAR AND PEACE}

\section{A MANUAL OF PERSONAL} PREPAREDNESS

$$
61.4: 0.2=8
$$

ISSUED AT THE

OPENING OF THE HEALTH AND FOOD EXHIBITION OF THE

AMERICAN MUSEUM OF NATURAL HISTORY

MAY 23, 1917

PRICE 25 CENTS 


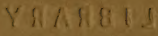

ज्ञात 90

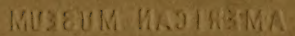

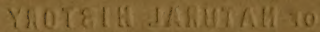




\title{
AMERICAN MUSEUM OF NATURAL HISTORY
}

\section{HANDBOOK OF HEALTH \\ IN WAR AND PEACE}

\section{A MANUAL OF PERSONAL PREPAREDNESS

\author{
C-E. A. WINSLOW
}

WITH FOREWORD BY

\section{HENRY FAIRFIELD OSBORN}

PREPARED AND ISSUED BY

Departments of Public Health and Public

EDUCATION OF THE AMERICAN MUSEUM

OF NATURAL HISTORY

NEW YORK, 1917 


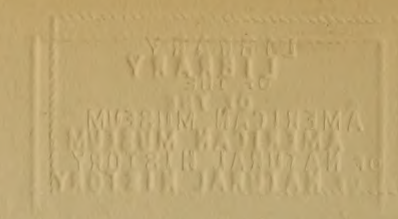

$11-73255-$ may 29

(1) 


\section{FOREWORD}

There has never been a period in American history when diffusion of knowledge of the laws of nature was a more immediate and a more imperative duty than at the present time. Hundreds of thousands of young men and young women are ready to offer their services and, if need be, their lives for their country and for the great principles of loyalty, truth, justice, humanity and liberty for which our President has enlisted us in this world war. But let not a single life be lost needlessly. Let no constitution be broken by disease through ignorance. The patriotic opportunity of all men of science is to spread the truth, and to spread it as quickly as possible. Let us speak plainly of all the dangers and enemies which surround the soldier and the sailor, of those that kill the soul as well as those which destroy the body. The loss to the world of the finest strains of manhood is the most awful curse of the many curses attending this war. Every young man, if single, must think of his future wife, of his future home, of his future children and so live that, if his life is spared, he may some day give to his country one of the greatest gifts it is in a man's and woman's power to give-healthy and patriotic offspring. It is a scientific, no less than a religious principle, that to serve one's country one must be sound in body, sound in mind, and sound in spirit.

In opening a food and health exposition, the American Museum is in coöperation with the Council of National Defence and especially with its Medical Board, also with the National Food Commission under Herbert C. Hoover.

Henry Fairfield Osborn, President. 



\section{HEALTH AS A NATIONAL DUTY}

War is no longer a conflict of armies but a struggle between nations. Behind the gallant battalions in the field there must be other battalions in the munition factories and on the farms whose devotion is equally essen-

Our Responsibility in the National Crisis tial to national victory. Success demands the coördinated individual efficiency of the whole people; and individual efficiency rests upon health.

As the Lnited States enters upon a great war for liberty, for justice and for humanity, there arises in all of us a new sense of common responsibility, a new determination to reach the highest level of effectiveness. There is no place any more for carelessness, for meddling, for self-indulgence. There is no place for preventable disease.

Health is to-day, as never before, a national dutyhealth not merely in the sense of freedom from acute sickness, but in the sense of full abounding vigor and vitality and power.

Health and Efficiency The maintenance of such vigor and vitality depends on simple principles of hygiene and sanitation. It has been truly said that "within natural limitations, a community can determine its own death rate." It is equally true that "within natural limitations, an individual can determine his own physical efficiency."

It is in the belief that thousands of men and women in training camps and in munition factories, on farms and in homes, are determined in this hour of trial to give their best to their country that this Handbook of Health and Efficiency has been prepared by the American Museum of Natural History and dedicated to an awakened and a reborn America. 


\section{FUEL FOR THE LIVING MACHINE}

The food is the fuel which runs our living machine, just Food as Fuel as truly as coal is fuel for an engine. Experiments in physiological laboratories have shown that in a man, as in any other well-made machine, you get out an amount of work and heat that corresponds directly to the amount of fuel put in.

Our first food need, then, is for a sufficient supply of energy. Food energy is measured in calories, one calorie being the amount of heat energy necessary to raise the temperature of one kilogram (about two pints) of water one degree on the centigrade thermometer. Three large lumps of sugar, one large banana, one very large egg, one chop, two thin slices of bread, two apples, one pat of butter, two-thirds of a glass of milk-each of these food portions contains about 100 calories. The average adult needs about 2,500 calories a day if leading a sedentary life, 3,000 calories if engaged in active physical work.

The individual soldier has his dietary needs cared for by those in authority. For the civil population and for the nation as a whole, however, the question of the food supply is a vital one in war time, and particularly at the present moment when the food supplies of Europe are exhausted and the whole allied world depends on America to preserve it from starvation.

The attainment of proper national dietary standards deEconomy in the pends partly on the available food supply Selection of the Diet and partly on the intelligent selection and use of foods. The cost of 100 calories in different forms varies enormously; and by learning to make an intelligent selection every individual purchaser and every individual householder can help in the great task of food conservation.

The following table, from "The Fundamental Basis of Nutrition," by Graham Lusk, shows the cost of 1,000 calories in 
the form of various staple foods. The actual prices would be higher now than in 1913, but the figures are significant of more or less constant relative differences. The economy in such foods as cornmeal, wheat flour, beans and pork as compared with mutton, beef and codfish is worthy of special note.

\section{Cost in Cents of 1,000 Calories}

\section{(Lusk)}

Glucose........... 12/3 Butter...........10

Cornmeal.......... 2 Milk............10

Wheat flour....... 21/2 Smoked ham....... 103/4

Oatmeal............ 24 $2^{4} / 5 \quad$ Cheese............ 112/3

Cane sugar......... 31/3 Loin pork..........121/4

Dried beans.........4 Mutton (leg)........161/4

Salt pork (fat) ...... 41/2 Salt cod.......... 191/2

Rice............. 5 Sirloin beef.........24

Wheat bread........ 51/3 Turkey..........40

Oleomargarin........ $71 / 2$ Codfish steak (fresh)...42

Potatoes........... $71 / 2$

The supply of a sufficient calorie allowance is, of course, only a part of the problem. The body not only gets energy from its food but also builds up out of the foods its own substance

Body-building Foods which is constantly being consumed as a result of the life process. Muscle and brain and all the other tissues of the body are wasting away minute by minute and second by second, and the waste must be made good from the substances in the food. Some of the elements in living tissue are present in almost all food substances and are sure to be supplied in sufficient amounts in any diet which will furnish 2,500-3,000 calories of energy. Other building stones of the body are found only in certain foodstuffs.

The most important of these building stones are found in the nitrogen-containing foodstuffs known as proteins, of which 
white of egg and lean meat are examples. So important are these substances that many authorities have divided foods into two main groups.

(1) Body-builders and repairers. (Protein, chiefly contained in meat, eggs, milk, peas, beans, kernels, grain, etc.)

(2) Energy-producers, yielding heat and work. (Fats, and oils [hydrocarbons] with sugar and starch [carbohydrates].)

A definite proportion of protein food (10-15 per cent.) is an absolute essential of the diet, and people who fail to get a sufficient amount of such food quickly show the result in diminished vigor. Pellagra, a serious disease which occurs particularly among the poor population of our southern states, is closely connected with a diet poor in protein, and can be cured by the substitution of one rich in meat, eggs and milk.

The table below, showing the classification of certain common foodstuffs according to their richness in proteins and fats, is taken from the excellent handbook on "How to Live," by Prof. Irving Fisher and Dr. E. L. Fisk. Foods low in both proteins and fats are composed chiefly of carbohydrates (sugar and starches).

\section{Common Foods Classified}

Poor in Fat

Rich in Fat

White of eggs

Very high Codfish

in Lean beef

Protein Chicken

Veal

$\begin{array}{lll} & \text { Shellfish } & \text { Most fish } \\ \text { High in } & \text { Skim milk } & \text { Most meats } \\ \text { Protein } & \text { Lentils } & \text { Most fowl } \\ & \text { Peas } & \text { Whole egg } \\ & \text { Beans } & \text { Cheese }\end{array}$


Poor in Fat

Rich in Fat

$\begin{array}{cl}\text { Moderate } & \text { Most vegetables } \\ \text { or } & \text { Bread } \\ \text { Deficient } & \text { Potatoes } \\ \text { in } & \text { Fruits } \\ \text { Protein } & \text { Sugar }\end{array}$

Peanuts

Milk

Cream soups

Most pies

Doughnuts
Very Rich

in Fat

Fat meats

Yolk of eggs

Most nuts

Cream

Butter

Mineral salts, such as lime, iron, etc., are also essential to the body and there are peculiar substances called vitamins present in certain foods, such as fruits, unpolished rice, etc., which are necessary for its normal development.

Importance of Variety in Food

The disease beri-beri among the Philippine scouts was due to the lack of such substances in a diet made up largely of polished rice, and was cured by a change in diet. As wide a variety of foods as possible should be included in the diet, and fads as to the avoidance of certain foodstuffs frowned upon. A certain proportion of hard, bulky and indigestible foods, such as crusts, fibrous vegetables and nuts, is essential to the proper working of the bowels. Ample protein, salts and vitamins will be secured by the normal instincts if unhampered by economic limitations, so that the whole question comes down to one of costs. Professor Lusk estimates that the average cost of a group of staple articles has increased from 11 cents in 1916 to 18 cents in 1917 for an amount that would supply 2,500 calories. To help meet the problem of this increased cost of living he has prepared the following low-cost meatless dietary of high caloric value, designed for a family of five persons, the father at work and the mother doing household work. Potatoes, with their valuable alkaline salts, had to be excluded from the diet because of their prohibitive price. The cost amounted to $\$ 1.16$ daily for 14,400 calories, or eight cents per thousand calories, which is not a high price: 
Low-Cost Meatless Dietary of High Efficiency Value for a Family of Five Persons, Father at Work ANd Mother doING Household Work

Essentials.-Do not buy meat until you have bought three quarts of milk a day. Milk contains valuable tissuebuilding food, valuable salts and invaluable vitamins which help toward sound health.

If you buy bread remember that day-old bread is much cheaper than freshly baked bread and is just as good a food.

The menus may be arranged as follows:

\section{BREAKFAST}

Cornmeal mush, fried ('+milk for children and corn syrup for adults), or oatmeal, or hominy, or farina, or buckwheat cakes.

Bread (or toast).

Oleomargarin.

Coffee (adults).

Stewed prunes.

Orange juice for baby.

\section{LUNCHEON OR SUPPER}

Pork and beans (bean soup for young children), or creamed dried beef on toast.

Bread.

Oleomargarin.

Tea with milk and sugar, for adults.

Milk for youngest children.

Cereal, coffee or cocoa for older children.

Sliced bananas with sugar, or stewed dried peaches. (The bananas may be boiled in their skins.)

DINNER

Lentil soup (or potato, or bean, or pea soup).

Boiled rice (or spaghetti, or macaroni with cheese, or baked split peas with bacon). 
Tomato catsup.

Bread.

Oleomargarin.

Tea for adults.

Milk for youngest child.

Dried-apple pie with cheese, for adults.

Dried-apple sauce for others.

The Approximate Cost per Day and the Nutritive Values in Calories Appear Below

\begin{tabular}{|c|c|c|c|}
\hline & Amount & Calories & $\begin{array}{l}\text { Cost in } \\
\text { Cents }\end{array}$ \\
\hline offee & $21 / 3$ ounces & $\ldots$ & 3 \\
\hline & $1 / 2$ ounce & & 2 \\
\hline & 3 quarts & 1,800 & 27 \\
\hline & 2 pounds & 2,500 & 9 \\
\hline & $1 / 2$ pound & 800 & 4 \\
\hline omargarin. & $3 / 4$ pound & 2,500 & 19 \\
\hline n syrup... & $1 / 3$ pound & 650 & 2 \\
\hline & $1 / 4$ pound & 450 & 2 \\
\hline e or macaroni... & 1 pound & 1,600 & 8 \\
\hline navy beans... & 10 ounces & 1,000 & 7 \\
\hline pork........... & $61 / 2$ ounces & 1,000 & 6 \\
\hline Pry fruit (prunes) ......... & 1 pound & 325 & 12 \\
\hline $\begin{array}{l}\text { lour, lard, etc., for pie or } \\
\text { other extras............. }\end{array}$ & & $\frac{1,800}{14,425}$ & $\frac{15}{116}$ \\
\hline
\end{tabular}

As cheaper meats, pork sausages, braised chuck rib of beef, salt cod or herring may be added if finances allow.

The amount and hence the cost of food available for the poor depend directly on the amount wasted by the well-to-do; and it is the duty of every American to give serious attention to this question. A diet containing a surplus of meat, fish and eggs is not only Sherman's Rule for Economy in Diet wasteful but positively harmful, since proteins in excess 
decompose in the intestines and poison the body. An excellent general rule in this connection has been suggested by Prof. H. C. Sherman, who advises that the average family should spend as much for fruits, vegetables and milk as for meat, fish and eggs, and as much for vegetables and fruits as for milk and eggs.

Wastage in purchasing and preparation of foods is another Stop the Waste important cause of dietary deficiency. The of Food following suggestions indicate some of the special ways in which the housewife can

\section{economize.}

Go to the store yourself and select the food, with a view to quality and cost. Be sure you get full weight and take home for soup or stew all bones and trimmings.

Buy the cheaper cuts of meat. They are in many cases more nourishing than the more costly ones, and can be made tender by proper cooking and seasoning. The cheaper cuts of meats cost only one-half as much as the round and sirloin.

Buy in quantity if possible.

Use fish instead of meat as much as possible.

Milk, cheese and beans are cheaper than meat and contain all necessary nutrients.

Use a fireless cooker, which saves time, fuel and food value.

Buy fruits and vegetables only when in season.

Buy foods in bulk, not in packages.

Omit luxuries and foods of low-energy value.

Save left-overs.

\section{PURE FOODS AND CLEAN FOODS}

In war time we should welcome the introduction of cheap Value of Second-Grade grade foods if they are really valuable and Foods

food substitutes or the marketing of secondif they are sold as such. Cold-storage products are usually not as palatable as fresh meats; but cold storage has vastly increased the food 
resources of the world by conserving the excess of one season and one locality for use at other times and places. Skim milk is a highly valuable food material which should be sold freely if properly labeled. There are butter substitutes on the market which are as valuable for food as real butter and cost but half as much.

The purity in foods is mainly a question of honesty. Clean food, on the other hand, is a vital essential of health.

Purity and

Cleanliness

Polluted water in the past has been a common cause of disease both in the camp and in civil life. All surface water supplies, lakes and streams are liable to pollution from sewers or from

Danger from Polluted Water material washed in from the banks, and wells and springs may be polluted through crevices in the soil. No water should ever be drunk if there is any uncertainty as to its quality. The water for troops in the field should be purified by filtration or disinfection, and it is one of the first duties of the soldier to avoid the use of any unauthorized supplies. Water of doubtful quality may be made safe by boiling or by the addition of chloride of lime. Dissolve a teaspoonful of chloride of lime in four pints of water and add one teaspoonful of this solution to a gallon of the water to be purified (one tablespoonful to four gallons, ten tablespoonfuls to a barrel). The water should stand for half an hour before use.

Milk is another food which often carries the germs of disease, germs of tuberculosis from the cow, or germs of typhoid fever, sore throat, diphtheria, etc., from human beings who

Danger from Milk have handled it. Milk should always be pasteurized or heated to $140^{\circ}-145^{\circ} \mathrm{F}$. for 20 to 30 minutes before it is used, and on no account should uncooked cow's milk be given to young children.

The best way to pasteurize milk in the home is to set the bottles in a deep pan of water on the stove, put a milk 
thermometer into the water, heat to about $145^{\circ} \mathrm{F}$. or

How to

a little over, and then set the pan on

Pasteurize

Milk

the back of the stove, moving it back and forth now and then to keep the temperature, for half an hour, as near $145^{\circ}$ as possible, say between $140^{\circ}$ and $145^{\circ}$. If no milk thermometer is at hand it will be almost as well to heat the pan till the water boils and then let it stand on the back of the stove for half an hour, although this may give the milk a slight cooked taste.

Foods of all sorts should be carefully protected from dust

Other Safeguards for Foods and flies, which may carry disease germs, and from unnecessary handling. It is important that foods should not be handled by those who are "coming down" with any communicable disease; and foods to be eaten raw should be purchased only from careful and responsible dealers. The greatest care should be taken to avoid tainted meats and to keep perishable foods from spoiling.

\section{EXERCISE AND REST}

The heart, the lungs, the blood vessels, the bowels degenerate if they are not given their proper Value of work to do, and on the other hand they Exercise suffer if too heavy a burden is placed upon them.

The muscles make up more than one-half the total weight of the human body, and their proper use is essential, not only for their own growth but on account of the interrelation between the health of the muscles and that of the rest of the organs. Vigorous physical exercise not only develops the muscles themselves, it stimulates the heart and the blood vessels, it deepens the breathing, it keeps up the tone of the digestive system, it frees the tissues from the accumulation of harmful waste products. 
The physique of the recruit is systematically developed by setting-up exercises, marching, rifle and sabre exercises, applied gymnastics, swimming and athletic games. It is overstrain

Avoidance of Overstrain

which the soldier must avoid, and "soldier's heart" has been a common complaint in Europe during the present war. Exercises should be varied so as not to overtax any one group of muscles and they should never be carried to the point of exhaustion. Breathlessness is a valuable danger signal of overload of the heart.

It is not hard work that kills. It is prolonged strain at dull tasks without variety, on the one hand, worry and excitement on the other. With a proper variety of work it is marvellous Rest and Efficiency what the human mind and hand can accomplish, but they cannot endure too long a pull without interruption. The operatives in the Zeiss Optical Works at Jena actually did more work in an eight-hour day than in one of nine hours. They could keep fresh and vigorous for the shorter period, while they began the nine-hour day in poor condition because imperfectly rested from the day before.

The studies made in the English munition factories during the present war have shown clearly that a limitation of hours of labor may often lead to such an increase in production; and this is a lesson we must bear in mind in this country in the present crisis.

The first rule of the hygiene of rest, then, is to avoid so far as possible overstrain due to prolonged work of a similar kind. People vary a good deal in their rest needs. Some men

Ways of Resting are rested by a change of work, some by active play and some by complete rest. Nothing, however, can take the place of necessary sleep, and the average individual needs about eight hours of sleep out of the twenty-four. No one can work hard all day and play half the night. Nervousness and irritability are danger signals. They mean that 
the strength is being overtaxed and that some change in habits should be made.

Cultivation of mental poise is a great help in conserving vital force. Worry is as bad as monotony and a fit of anger poisons the whole system and is more exhausting than a hard day's work.

\section{POSTURE AND RESPIRATION}

Standing still properly is one good form of exercise.

Posture a

Form of

Exercise Posture depends on the muscles which control the position of different parts of this framework. With the same equipment of bones, one body may be stoop-shouldered and slouching and another may be erect and well-knit. One of the most immediate good results of military training is correct posture, which involves the exercise of all the hundreds of muscles which help to hold the body well.

The backbone, as we have seen, is meant to be slightly Evils of Bad curved, so as to give elasticity. In people Posture who do not sit or stand straight, these curves become greatly exaggerated, leading to round shoulders and a drooping head. Such bad posture is not only ungraceful but unhealthy. If the back and shoulders and abdominal wall are not held properly the lungs do not get sufficient aëration and the internal organs are crowded together and their blood supply hampered. Many and grave disorders are traced to faulty posture and are cured by improving it.

When standing correctly, the head, body and legs should

Correct be poised one above the other so that a Posture line dropped from the front of the ear falls within the forward half of the foot. "This is the position of the long-distance walker, the mountain climber, the best all-round athletes; it is the position of command and authority, and is found predominant in the 
great leaders of commerce and public life. On the other hand, collapsed positions are characteristic of both physical and mental weakness. They constitute a distinct aspect of weakness and illness, from the tuberculosis patient to the feeble-minded." *

In sitting, the body should be bent only at knees and hips, and the head, neck, and trunk should be kept in one straight line.

Another important element in hygiene is the exercise of the organs of breathing. In ordinary breathing only about ten per cent. of the lung contents is changed at each breath, and the

Deep

Breathing remoter air sacs of the lungs which are not properly exercised are peculiarly liable to disease. The high mortality from tuberculosis among clerks, bookkeepers, telegraphers and other indoor workers whose tasks require or invite a stooping posture are examples of such harmful effects. "A hundred deep breaths a day" is one physician's recipe for tuberculosis, according to Fisher and Fisk. Deep breathing should be slow and not forced.

\section{FRESH AIR}

Variations in the chemical composition of the air are of little practical moment, except for the presence of poisonous fumes and dust under special industrial conditions. Even in the

Why Bad Air Is Harmful

worst ventilated room the proportions of carbon dioxid and oxygen never change sufficiently to produce harmful physiological effects. The discomfort and injury to health that come from living in badly ventilated rooms are due not primarily to any chemical changes but to the rise in temperature that obtains under such conditions.

This does not mean that fresh air is unimportant, but quite the contrary. A badly ventilated room is generally

* Jessie H. Bancroft, in The Teaching of Hygiene. 
an overheated room. In such a room the blood vessels

Effects of Overheating of the skin are dilated, the body temperature rises, the pulse increases, the blood pressure falls. The brain and inner organs are robbed of blood. One feels dull and listless and disinclined to exertion. The New York State Commission on ventilation showed that when there was a powerful incentive exertion was possible for short periods at high temperatures, but that under ordinary conditions 6 per cent. more work was done at $68^{\circ}$ than at $75^{\circ}$ and 15 per cent. more than at $86^{\circ}$. Prof. Ellsworth Huntington, from exhaustive studies of the effect of season and climate upon physical and mental work, finds a mean outdoor temperature of $60^{\circ}-64^{\circ}$ most favorable for efficiency, summer and winter both showing a marked falling off as compared with fall and spring. It cannot be doubted that the excessive temperatures maintained in many factories (often combined with high humidities, which accentuate the effect by checking evaporation of perspiration) militate very seriously against industrial efficiency. In military life the important influence of climate upon bodily vigor should be borne constantly in mind in the selection of training camps.

The avoidance of gross overheating (temperatures above Value of Air $68^{\circ}$ ) is not the only factor to be considered. Movement

The body must be protected against the debilitating effect of heat on the one hand and against the shock of excessive chilling on the other. Within reasonable limits, however, variations in temperature, and particularly movement of the air, are important factors in promoting health. The body owes its marvellous power of maintaining its own temperature constant through a wide range of outside temperatures to the reaction of the skin blood vessels, which contract to keep the blood out of the skin when it is cold and expand and bring the blood to the surface when a more rapid heat loss is desired. The tiny muscles in the walls of these blood vessels must be ex- 
ercised like any other muscles if they are to be kept in good condition. In a person who lives habitually in an even high temperature the blood vessels do not respond readily to sudden change. In such people, the mucous membranes of the nose are constantly congested (filled with blood and lymph) as the blood vessels dilate to keep the body at the proper temperature. As a consequence, these membranes, instead of shrinking and drying promptly as they should when they come in contact with cold outer air, lose their quickness of response and stay moist and swollen even after the blood vessels themselves have contracted; this makes them an excellent breeding place for bacteria. People who have been weakened in this way are very sensitive to the cold air and are easily subject to chills. Benjamin Franklin once said, "People who live in the forest, in open barns, or with open windows, do not catch cold, and the disease called a cold is generally caused by impure air, lack of exercise, or from overeating." Science has amply confirmed these observations of our great natural philosopher.

Fresh air, then, means air that is not too hot, or too cold, or too even in temperature,-air that is pleasantly cool and in moderate motion. If the thermometer reaches $70^{\circ}$ (except in the

What Fresh Air Is case of elderly people, who may require a higher temperature) it is a sign that the window should be opened. It is particularly important to have plenty of fresh air in the sleeping room and windows should be kept well opened at night even in cold weather.

\section{HYGIENE OF CLOTHING AND BATHING}

The clothing should protect against extremes of cold, and this is particularly necessary after exercise when the skin blood vessels are dilated and the body bathed in perspiration. Woolen

Qualities of the Clothing clothes may be desirable under such conditions because 
wool being porous is a poor conductor of heat and also because it takes up moisture readily and so absorbs and holds the perspiration.

Cotton, and particularly linen, are rapid conductors of Evil of Too Heavy Clothing heat and do not absorb moisture, so that they are more suitable for warm weather.

It is quite as undesirable to wear clothes that are too warm as to expose the body to undue chill. If the skin cannot get rid of its heat fast enough as a result of too heavy clothing the dull and sleepy feeling associated with "bad air" results. The habit of wearing too many clothes weakens the power of the system to respond quickly to changes in temperature, and renders one susceptible to colds. Most people wear too heavy underclothing in winter. Cotton or linen underwear is generally better than woolen; and up to the age of fifty or even sixty years it is wiser to wear underclothing of the same weight both winter and summer, relying on an overcoat for warmth when out of doors and not exercising.

The first object of bathing is to wash off the dirt and soot

\section{Warm and}

Cold Bathing

which soil the body and to remove the waste materials deposited on the skin by perspiration. Warm or tepid water is most effective for cleaning the hands or body. Bathing in warm water increases the size of the blood vessels in the skin and draws the blood away from the brain, making one feel comfortably sleepy. This is the reason why a warm bath is usually taken at bedtime. After every hot bath cold water should be applied to the entire body. A cold bath, on the other hand, contracts the skin blood vessels and drives the blood to the internal organs and the brain, making one feel alert and keen. Cold bathing is a powerful tonic to the skin, since it trains these blood vessels to respond quickly to changes in temperature. People who take cold baths regularly are likely to be hardy and little subject to colds. 
In the matter of bathing, however, we must again remember that the body should be stimulated by cold water, but not chilled too severely. A cold bath should be followed by a re-

Avoidance of Extremes

action; that is, the surface blood vessels should enlarge again, so that the skin becomes warm and glowing. Brisk rubbing with a rough towel helps to secure this reaction. If no reaction follows, or if one feels tired after bathing, the bath was too cold or too prolonged, or the body is not strong enough to endure the shock: In such cases cold baths may do serious harm.

No bath of any kind should be taken within an hour after eating. The blood is needed in the intestines for the process of digestion, and it is harmful to disturb the circulation, as any bath must do at such a time.

The cleanliness of underclothing is of specially vital importance to the soldier. The suppuration of wounds is frequently due to germs coming from dirty clothing, and the terrible TrenchFoot disease "trench-foot," which has afflicted the French troops in the present war, has been shown to be due to neglect in this regard. Molds from damp and dirty socks get into cuts and cracks in the foot, stop up blood and lymph vessels, and gangrene follows in the tissues thus deprived of the protective action of the body fluids.

Shoes of proper shape and material are also primary military essentials. Colonel Keefer says, "No one article of the soldier's clothing plays so large a part in his efficiency as the shoe."

The Hygienic Shoe

As the result of an exhaustive study made by a special army board created to study this subject, the problem of army shoes has been satisfactorily solved. The civilian, however, still often suffers from improper footgear. The deformity known as flat foot, often accompanied by pains reaching far up the back, may be caused by the resulting strains. A hygienic shoe should be everywhere as wide 
as the sole of the foot, and wide enough in front to permit the toes to move freely. The inner edge of the shoe should be straight, so that a line drawn back from the middle of the great toe touches the heel. The heels should be low and broad. The sole and uppers should be flexible, so that the foot may be bent freely at the point where the toes join the instep. A high shoe should not be so tightly laced at the top as to interfere with circulation. A porous shoe, like one made of russet leather, is much better than an enamel or patent-leather shoe, because it allows the escape of moisture and prevents overheating of the foot.

\section{CARE OF THE TEETH AND BOWELS}

Many obscure maladies of the joints, the heart and the kidneys are traced to bacterial infections arising from decayed teeth, and the care of these strong but delicate structures is a primary essential of personal hygiene.

The enamel is the natural protection of the teeth, and it

The Care of the Teeth is very important that it should not be injured by cracking hard nuts with the teeth or picking the teeth with hard objects which might splinter them.

On the other hand, thorough chewing of the food, and particularly of fairly hard foods like crusty bread, helps to polish the surfaces of the teeth and to prevent deposits on them. The coarse food which savage people eat helps to keep their teeth in good condition, but since civilized man eats few hard foods, especial care is necessary to prevent tooth decay and keep the mouth healthy.

The most important help in keeping the teeth in good

The Toothbrush and Its Use condition is, of course, the toothbrush. It has been said that in an army the soldier's toothbrush should be inspected every morning as systematically as his gun. The teeth should be brushed regularly night and morning at least. 
It is well to brush them after each meal, because the sooner deposits of food are removed, the better. Once a day a good tooth powder may be used to aid in cleaning the teeth. For soldiers in the field, where no tooth powder is available, wood ashes or wood charcoal has been recommended.

The toothbrush should not be too large, and the bristles should be of medium hardness and so shaped that they will get between the teeth. Both sides and the top of the teeth should be thoroughly brushed. It is much better to brush down or up from the gums to the cutting edge than sideways across the teeth, because when the brush passes sideways the bristles do not get in between the teeth. The most effective method is to place the bristles of the brush firmly against the teeth, apply pressure as if trying to force the bristles between the teeth, and then give the brush a rotary or scrubbing motion. Care should be taken to go over both the back and the front of the cutting teeth in both jaws, as well as the flat crowns of the grinding teeth. The gums above and below the teeth and the surface of the tongue should also be cleaned.

When the brushing is finished, lukewarm water should be taken into the mouth and forced between and around the teeth several times by means of the lips, cheeks, and tongue.

Details of the Tooth Toilet This is as important as the proper use of the toothbrush itself. The tooth toilet should take from three to five minutes.

Even the best use of the toothbrush will not always keep the spaces between the teeth entirely clean. If food particles collect in these spaces, a bit of dental floss may be passed up and down between the teeth, care being taken not to injure the delicate gums.

With all precautions tooth decay is likely to begin in places; and the teeth should be regularly examined by a competent dentist twice a year to detect such troubles in time. 
Another common cause of obscure ailments, headache, How to Avoid dullness and feeling of oppression is decomConstipation position of food wastes in the intestines. If the bowels are not emptied regularly, bacteria form poisonous products of decay, which are absorbed along with the food and produce far-reaching harmful effects.

It is important to form the habit of cleaning out the intestines regularly at least once a day and perhaps oftener, so as to keep the intestinal tube clean. If this does not happen naturally, the remedy should be found, not in medicines, but in drinking plenty of water and eating more fruit, green vegetables, and coarse foods, or in more exercise, sleep and fresh air.

Too frequent loose movements of the bowels (diarrhea) Diarrhea are often due to the growth of special kinds of harmful microbes in the digestive tract. The best remedy is cut down the food, particularly meats and eggs, and to take a dose of castor oil or some other medicine which will help the body to get rid of both microbes and poisons. If the trouble continues, a doctor should be consulted.

\section{AVOIDANCE OF DRUGS AND STIMULANTS}

Among the influences which work to deprive the body $\begin{array}{ll}\text { Alcohol a } & \text { of its maximum efficiency, none is more } \\ \text { Narcotic Drug } & \begin{array}{l}\text { important than certain dangerous drugs, } \\ \text { among which alcohol is the chief offender. }\end{array}\end{array}$ Alcohol, like many other drugs, acts chiefly on the nervous system; it does not serve to make any part of the nervous system work more readily, but numbs or puts to sleep certain parts of it. It acts first of all on the inhibitions, with the result that some of the nerve actions which would ordinarily be inhibited or held in check are allowed to go on more freely. This seems like a stimulation or increase of power, but it is 
really only a breakdown of the system of control. The situation is somewhat similar to the case of a runaway horse. The horse is no stronger, but is much more dangerous, when it is running away than when it is held firmly by the reins in the hands of a skilled driver.

A long series of experiments, of which the most recent have been carried out by Prof. F. G. Benedict, in the Carnegie Nutrition Laboratory, have made it abundantly clear that even Alcohol and Efficiency very moderate doses of alcohol tend seriously to interfere with the working of the nervous machinery of the body and to make its reactions slow and clumsy. Of eleven different tests of efficiency made by Professor Benedict, all but two showed a decrease in quickness or accuracy of from 3 to 46 per cent. in the persons who had taken alcohol. The relation of the use of alcoholic liquors to industrial accidents is well recognized; and the attitude of public service corporations and other large employers of labor toward alcohol offers eloquent testimony to its harmful influence. No one who has ever been a steady user of alcohol is accepted as a member of an arctic expedition, and alcoholic drinks are never used by those engaged in these enterprises. Such persons have been found by experience to be lacking both in efficiency and in the ability to endure the necessary hardships.

Nor are the results of the use of alcoholic liquors limited to a temporary interference with mental and physical powers. Exhaustive studies of the death rate among abstainers and non-abstainers conducted by English and American

Alcohol and the Death Rate life insurance companies have yielded most significant results. One such recent investigation made by forty-three American life insurance companies showed that the death rate of those who used alcohol steadily and freely was 86 per cent. above the normal, while the rate among steady moderate drinkers (persons taking the equivalent of two glasses of beer or one glass of whiskey a day) was 18 per cent. above the normal. 
It is evident that alcohol does a great deal of harm to certain individuals and a certain amount of harm to all who use it habitually. No man who wants to do anything difficult, and to do it well, uses alcohol beforehand. No surgeon about to perform a difficult operation would dream of taking a drink. No athlete would think of drinking before running a race. When a person wants to be at his best, to have his nerves and muscles and his whole body working most smoothly and effectively, he does not use a drug.

So it is with nations. The evil effects of alcoholic drinks upon national efficiency, and the wastefulness involved, were strikingly recognized in the European War. The Russian government stopped the sale of vodka (the Russian strong drink), and the governments of France and England passed laws to restrict drinking. As soon as the European nations wanted to be at their best, to meet a great crisis, they laid aside the burden of alcohol.

Now that the United States has entered the world conflict the policy of "down glasses till the war is over," should be the slogan of every man determined to give his country his best service in an hour of crisis.

It is important to remember that both alcohol and many The Patent other harmful and often habit-forming Medicine Evil drugs are often taken unknowingly in various kinds of patent medicines. Some of the commonest and most widely advertised "tonics" and "spring medicines" owe any effect they have to the fact that they are composed largely of whiskey. Remedies supposed to cure catarrh, tuberculosis, and other diseases often contain opiates that may lead to a drug habit. Medicines advertised to soothe babies usually contain morphine or opium, and headache cures frequently contain deadly poisons, such as acetanilid. The use of such preparations, except on the order of a physician, is most unwise. Patent medicines and their misleading advertisements do immeasurable harm by arousing a false sense of confidence and de- 
laying the medical or surgical care, prompt use of which is essential in such diseases as cancer and tuberculosis. The well person has no need of drugs of any kind, and if one is ill enough to need drugs, he is ill enough to benefit by medical advice.

\section{HYGIENE OF ADULT LIFE}

Statistics show that at ages over 45 the death rate in the United States is apparently increasing and not decreasing, as is the case at earlier age periods. The increase is manifested almost wholly in the degenerative diseases of the

The Death Rate at Ages over Forty-five heart and blood vessels and kidneys, and in cancer. Most of the degenerative diseases cannot be cured in the sense that diseases of early life are cured. Old age prevails in time. The important fact is that in too many cases old age comes on prematurely and without the victim suspecting its insidious onset.

The premature onset of old age, when not due to specific congenital defects, is usually the result of unhygienic living and particularly excesses of various kinds. Under the unnatural conditions of modern life too many of us suffer Causes of Premature Old Age from too little air, too little exercise, too much work and too much food.

The degenerative diseases of adult life are gradual in their onset and could generally be checked if the enemy were detected in time. When disease of the heart or arteries or kidneys or any other organ first sets in, the ordinary rules of personal hygiene must be supplemented by special rules of daily living Value of Medical Examination to Detect Disease in Time which take into account the particular defect. Even cancer, one of the most deadly of the diseases of adult life, can be cured in a large proportion of cases by a surgical operation 
if the condition is recognized early in the disease, while if treatment is delayed, there will be little hope.

The only way in which these physical defects can be detected early enough to check their course is through a complete examination of the whole body by a competent physician. It is the conviction of public health authorities that every person over forty-five should consult a physician at least once a year, for a complete examination of the whole body, to learn in time of the beginnings of disease and the precautions necessary to prevent it from extending. Such a course would, it is conservatively estimated, add five years to the average life of persons between forty-five and fifty years of age.

\section{MAN AND THE MICROBE}

There are many different kinds of microbes (or little living Good and Bad things, which is the meaning of the word), Microbes some of them classified by the biologist as animals and some as plants. Most microbes are harmless and some are actively beneficial to man, as, for example, the bacteria which ripen cream and make vinegar and those which fix the nitrogen of the air and make it available for the food of higher plants. A few of the microbes, however, are parasites which live in the tissues or on the surface of the human body as a mold grows in jelly. As the mold forms chemical products which give the jelly a musty taste, so the microbes form chemical substances called toxins, which poison the body and produce the symptoms of disease.

Disease germs are normally propagated only by transfer Where Disease from one human being (or animal) to anGerms Come other. They may survive for a time outFrom side the body, but with rare exceptions they do not multiply under such conditions, but gradually and progressively perish. In an experiment by the English bacteriologist Houston, of 470,000 typhoid germs placed in ordinary tap water, only 480 were alive after one 
week, 31 after two weeks, 5 after three weeks, and none after four weeks. The danger against which we must guard is the rather direct transfer of infectious material from one person to another (or in a few instances from one of the higher animals, such as the cow, to man).

The source of disease germs is then the human (or in a few cases, the animal) body. An important part in the spread of communicable disease is played by early cases (not yet displaying any characteristic symptoms of illness) and

Human Carriers of Disease by "carriers," persons who have recovered from their illness or may never have themselves suffered from a particular disease at all, and yet are cultivating in their bodies and spreading to others the germs which are capable of causing the malady in question. An outbreak of over three hundred cases of typhoid in New York City was caused by a milkman, a typhoid carrier, who had had typhoid in Michigan fortysix years before and had been cultivating the germs in his body ever since. One or two out of a hundred well persons in a given community may be cultivating the germ of diphtheria in their noses or throats, and one or two out of a thousand may be cultivating the germ of typhoid fever in gall bladder or intestines. In such diseases as pneumonia and epidemic cerebro-spinal meningitis, the proportion of well carriers may be much higher, and infant paralysis appears to be chiefly spread in this manner.

Bacteria are solid particles not easily detached from moist surfaces. Quietly expired air is germ-free, and disease microbes are not transmitted by the atmosphere except where there is gross local pollution by the spray thrown out in

How Disease Germs are Spread coughing or sneezing or by clouds of infected dust. Clothing, books, toys, or other objects handled by the infected person play a much smaller part in the spread of disease than was thought a few decades ago. There is no absolute sharp line to be drawn between objects of this sort, which are 
dangerous, and those which are not, since the dying out of disease germs outside the body is a gradual one. We know, however, that the danger varies inversely with the time which elapses, and that the legends of disease caused by toys, locks of hair, etc., put away for months and years, are almost certainly apocryphal.

There are three principal vehicles which commonly serve to effect a rather direct transfer of infectious material from one person to another, and which between them account for 99 per cent. of all cases of communicable disease. These are articles of food and drink, flies and other insects, and more or less direct personal contact-food, fies, and fingers.

\section{DISPOSAL OF WASTES}

The germs of disease leave the infected person or the

Danger from Body Discharges carrier, in most instances, in the body discharges. The care of sputum and the fine spray thrown out in coughing or sneezing is essential in the control of such nose and throat diseases as tuberculosis, diphtheria, measles, whooping cough, scarlet fever, septic sore throat, and the like; while in the control of the bowel diseases, typhoid fever, cholera, hookworm disease, and dysentery, the care of intestinal and bladder discharges is of primary importance.

In army camps and in all unsewered districts, particularly

Typhoid in Armies in warm climates, the proper care of excrement, so that the germs it contains may not be carried by flies or in other ways to food, is a first essential of sanitation.

Typhoid fever earned the name, "the scourge of armies," on account of the epidemies which occurred up to the present century whenever large bodies of men were brought together without adequate precautions in regard to the disposal of bodily wastes. In our war with Spain, we had 20,738 cases of typhoid with 1,580 deaths among 108,000 men in a period of less than four months, nine-tenths of all 
deaths among the troops encamped in the United States being due to this cause.

In the disposal of excrement it is essential to avoid pollution of water supplies, and above all the exposure of the wastes in such a manner that infection may be carried by flies or in

Camp

Sanitation other ways to food. In fixed garrisons satisfactory methods of disposal will usually be provided. For use in camp good portable incinerators have been devised; but when these are not available, sink or latrine trenches may be dug to receive the excreta, in such a position as not to menace any source of water supply. In fly season the trenches should be provided with seats with the lids and the open space beneath the seats boxed in or covered to the ground with muslin or sacking. When it is impossible to prepare pit covers, crude oil, kerosene or chloride of lime well distributed over the sides and bottom will help to keep flies away.

Indiscriminate soil pollution is a military offense which may be of serious magnitude, since an individual in perfectly normal health may be a typhoid carrier and through carelessness may infect scores of his fellows. For the same reason the habit of washing the hands after resort to the toilet is of the greatest importance.

In civil life, where sewers are not available, the provision of tightly built fly-proof outside toilets is of vital sanitary importance. The screening of such closets in Jacksonville, Fla., and elsewhere has been followed by phenom-

Disposal of Household Wastes enal decreases in the typhoid death rate. For thickly settled communities the installation of a sewerage system of course offers the ideal solution of the difficulty from the standpoint of the individual householder. The sewage collected by such a system may be so treated as to be purified to any desired degree by screening, sedimentation, filtration or disinfection before it is discharged into adjacent watercourses. 


\section{INSECTS AND DISEASE}

Insects were in the past a far more important factor in Plagues of Olden Times the spread of disease than is the case today. Bubonic plague, which destroyed a quarter of the population of Europe in the Middle Ages, is primarily a disease of the rat, spread from rat to rat, and from rat to man by the bite of the flea. The dreaded typhus fever, which once decimated jails and camps, is spread by the bite of the body louse. With improvements in habits of personal cleanliness these pestilences have disappeared from civilized countries. Plague broke out in 1894, ravaged India, and found its way to ports all over the known world, but nowhere outside of Asia could it gain a foothold. Typhus was almost forgotten until the confusion and ruin of the European War permitted its appearance on the Eastern battle front. It is controlled by destroying lice through rigid measures of disinfection of the bodies and clothing of those who have been exposed to infection.

The most important insect carriers of disease today, out-

\section{The}

Filthy Fly side of certain regions in Africa, are the fly and the mosquito. The common house fly or filth fly is only an accidental carrier of such disease germs as it may happen to pick up on its feet or body; but in warm climates, where excreta are improperly disposed of, it is an important factor in the spread of typhoid fever, and studies in New York City and Richmond, Va., have shown that it may play a considerable rôle in distributing the germs of infant diarrhea. The first essential in controlling the fly is to do away with its breeding places by proper care of stable manure, in which it lays its eggs by preference, and by the elimination of other decaying rubbish. Manure should be stored in a closed dark bin with an impervious floor and removed once a week. The tight floor and complete removal are essential, since the fly mag- 
got burrows down into the ground or out into the outer drier portions of the manure to go into its resting or pupa stage, before it hatches out as an adult fly. Fly maggots in manure may be destroyed by the use of borax or hellebore.

Adult flies may be trapped or poisoned. The traps most commonly used consist of a wire cone in a box or cage largely of wire, with bait under the large lower opening of the cone. On

Fly Traps and Fly Poisons leaving their food the flies go upward toward the light, through the small opening, and into the cage, in which they perish. For fly, poisons the U. S. Public Health Service recommends formaldehyde or sodium salicylate. For household use these solutions may be prepared by the addition of three teaspoonfuls of either the 40 per cent. solution of formaldehyde found on the market or the powdered sodium salicylate to a pint of water. Nearly fill a glass tumbler with the solution, place over this a piece of blotting paper cut to a circular form and somewhat larger in diameter than the tumbler, and over this invert a saucer. Invert the whole device and insert a match or toothpick under the edge of the tumbler, to allow access of air. The blotting paper will remain in the proper moist condition until the entire contents of the tumbler have been used and the strength of the formaldehyde solution will be maintained. A little sugar sprinkled upon the paper will increase the attractiveness of the poison for the flies.

The conquest of mosquito-borne disease is one of the most brilliant triumphs of sanitation. The fact that yellow fever, the curse of tropical America, was transmitted by the bite of the Edes mosquito was demonstrated by

The Conquest of Yellow

Fever Major Walter Reed and three other surgeons of the U. S. Army in 1901, by experiments on themselves and other volunteers, Jesse W. Lazear, one of the intrepid investigators, giving his life for the cause. As a result of this discovery the pestilence which had caused 750 deaths a year in 
the City of Havana alone was wiped out in a few months, the building of the Panama Canal was made possible, and tropical America was rendered habitable for the white race.

Malaria, our principal insect-borne disease, is held re-

\section{Mosquitoes} and Malaria sponsible for an annual money loss of $\$ 100,000,000$ in the United States alone. It is transmitted by the bite of the Anopheles mosquito, which breeds in pools of stagnant water and woody sluggish streams. The adult mosquito of this type can be distinguished from the common or Culex mosquito by the fact that its wings are spotted and by its posture when lighted. Its body stands out in a straight line at an angle to the surface on which it rests, while the body of the common mosquito stands in a humpbacked position, with the posterior part of its body roughly parallel to the wall or ceiling.

The control of malaria depends on the elimination of breeding places by drainage of swamps, by cutting out and clearing ditches, streams and pools, and by the elimination of small receptacles of stagnant water. Mosquito larvæ, or "wigglers," may be destroyed by the use of oil or poisonous larvicides or by stocking ponds with fish, which feed upon them. Adult mosquitoes should be kept out of houses, and particularly excluded from malaria patients by screening, and in seriously infected regions, quinine should be systematically employed as a prophylactic.

\section{SPREAD OF DISEASE BY CONTACT}

While the diseases carried by food and by insects have in Contact-borne large measure been brought under control, Disease the diseases which are chiefly spread by contact, particularly such diseases as diphtheria, measles, scarlet fever and whooping cough, which are disseminated by the discharges from the nose and throat, have been much less successfully controlled. The methods 
by which infection finds its way from one mouth to another are almost without number. The common drinking cup and the direct discharge of mouth spray in coughing or sneezing furnish two obvious modes of infection. A hundred times a day fingers and other things that are not bacteriologically clean go to the mouth or nose, and to one who considers the possibilities the wonder is, not that we contract diseases, but rather that we so often fail to do so.

The only reliable defense against contact disease is the cultivation of habits of personal cleanliness that will keep everything but food and the toothbrush away from the mouth, and that will make the thorough washing of the hands before handling food an absolute and inevitable routine.

In all communicable diseases, but particularly in those which are spread by contact, it is important to surround all known infected persons with special precautions, so as to reduce as far as possible the danger of the spread of

Isolation of

Communicable Diseases disease germs from them. For this reason the reporting of communicable diseases to the health authorities is required by law, and boards of health maintain special laboratories to assist in the early diagnosis of suspicious cases of disease. When the infected person is found he must be isolated or cared for under such conditions that family and friends will not be endangered; and if this cannot be done at home, he must be removed to an isolation hospital.

In isolation emphasis is laid particularly upon limiting direct contact with the patient to the nurse or person in immediate charge, upon the prompt disinfection of body discharges and clothing, bedding, etc., soiled with discharges, and upon the disinfection of objects which leave the sick room, and particularly of the hands of the attendant. If such precautions are not conscientiously observed during the course of the disease, fumigation at its close will be of little use, since susceptible persons in the house will already have been infected. If isolation has been thorough, terminal fumi- 
gation is unnecessary, since there will be no gross soiling of the sick room with discharges, and occasional germs coughed out onto the floor or wall will soon die out and disappear.

Each communicable disease has its own definite period of How Long Sick duration, and experience teaches that a cerPeople Should Be Isolated tain number of days or weeks must pass before it is safe for the patient to mingle with other people. The periods of isolation for the more common communicable diseases are shown in the following table. In each case, of course, the patient should be isolated until he has entirely recovered from the disease, and running of the nose and ears has ceased. In diphtheria the only safe rule is to wait until tests made by a bacteriologist show that the nose and throat are free from diphtheria germs.

Isolation Periods of Common Communicable Diseases Disease Isolation Period from Time of Beginning of Attack

Chickenpox...........12 days

German measles........ 8 days

Measles............... 10 days

Mumps............. 2 weeks

Scarlet fever........... 30 days

Whooping cough........ 8 weeks, or until one week after last whoop

The fact that many diseases are particularly catching just

Danger of

Early Stages

of Disease when they are beginning makes it very important to watch for the onset of disease and to start isolation as soon as possible.

Measles, for instance, begins like an ordinary cold in the head, with sneezing and running nose and eyes. It has been shown by the investigations of Anderson that there is far more danger of spreading the germs of measles at this time than there is later, when a rash has appeared and the patient has been put to bed. 
Children should never be sent to school and should not play with other children when they have any of the signs which may mean an attack of communicable disease, particularly if there is reason to think they may have been exposed to infection.

The principal signs of the beginning of an attack of communiçable disease are the following:

$\begin{array}{ll}\text { Coughing, } & \text { Watery eyes, } \\ \text { Sneezing, } & \text { Headache, } \\ \text { Running nose, } & \text { Vomiting, } \\ \text { Sore throat, } & \text { Diarrhea, } \\ \text { Feverishness, } & \text { Swelling or pain back } \\ \text { Rash or spots of any kind, } & \text { of or under the ears. } \\ \text { Weak, tired feeling, } & \end{array}$

In each particular disease a certain time must elapse between the day when a person first gets the germ into his body and the day when the actual symptoms of disease appear. This is called the period of incubation. During this time the germs are growing in the body until

Incubation Periods in Common Diseases there are enough of them to make the person feel sick. The incubation period varies with different diseases, from a few days to several weeks. The periods for the commoner diseases are shown in the table below.

Disease Incubation Period

Chickenpox................. 11-22 days

German measles............... 11-22 days

Measles................... 8-15 days

Mumps.................. 15-22 days

Scarlet fever................ 7 days

Whooping cough.............. 14 days

Those who have been exposed to any of the communicable diseases should be kept under observation, and if possible 
isolated from others until the period of incubation has passed without any signs of the disease appearing. In the case of chickenpox, German measles, measles, mumps or whooping cough, this is not necessary if the person has had the disease before, and is, therefore, immune. In diphtheria the incubation period is short (from one to five days), but carrier cases are so common that all those who have been exposed to diphtheria should have their throats examined and a sample taken from the throat for bacteriological examination.

Everyone takes typhoid and scarlet fever seriously, but Importance of measles and whooping cough are often reMeasles and

Whooping Cough garded as unimportant and negligible infections. This is by no means the case. Measles is an important cause of invalidism in the army. "In the Union Army during the Civil War, there were 76,000 cases with more than 5,000 deaths. Among the Confederates whole brigades were temporarily disbanded on this account in the early part of the war." Among the civil population measles is in most cities the cause of more deaths than either typhoid or scarlet fever, while whooping cough stands very close to it. Above all it should be remembered it is to young babies that these maladies are most deadly. Measles and whooping cough are more than five times as fatal in infants under one year of age as in children over five. Every possible effort should therefore be made to protect infants from contact with those who have any symptoms of what may prove an infectious disease.

\section{IMMUNITY AND ITS CONTROL}

Every attack of communicable disease is a struggle beVital

Resistance

tween the invading microbes and the body; for as soon as foreign germs enter, the soldier cells of the blood attack the invaders while the tissues of the body begin to produce chemical sub- 
stances which tend to destroy the germs or neutralize their poisons. The degree of this natural vital resistance varies widely. Disease germs, like other enemies, are more likely to attack weak people than strong ones, though some diseases, like measles and smallpox, affect all alike.

Besides this sort of general vital resistance, a person who has recovered from an attack of some specific communicable disease enjoys a special immunity against the particular germ in question as a result of the struggle through

Immunity Against Specific Diseases which it has passed. In a number of diseases it is now possible to produce at will a state of immunity by the introduction into the body of weakened or killed cultures of the germ which have lost the power to produce active disease, but are still able to stimulate the tissues of the body, so that they can defend themselves against a later attack of living and virulent microbes.

This principle was applied over a century ago in the case of smallpox by Edward Jenner, an English physician. It has been said that this discovery of vaccination by Jenner was the

Smallpox Vaccination greatest single practical benefit ever bestowed by one man upon the human race. As soon as vaccination was generally introduced, the dreaded epidemics of smallpox ceased, and this disease now exists only as far as vaccination is neglected. During the eight years before the American Army entered Havana, there were 3,132 deaths from smallpox in the city; during the next eight years, when vaccination was enforced, there were seven.

Vaccination has conquered smallpox so successfully that people have almost forgotten what a terrible disease it was, and some of them have grown careless about vaccination. Others object to being vaccinated for fear some infection may get into the wound. All vaccine used in the United States is now tested as to its purity by the National Government, and there is no danger from its use, provided that 
the place where the vaccine is rubbed into the arm or leg is kept clean and free from dirt germs. The protective effect of vaccination wears off after a time. Every child should, therefore, be vaccinated when about a year old, and again at about the seventh year.

The most brilliant practical application of the principle

Anti-Typhoid Vaccination of vaccine therapy, since the time of Jenner, has been the preparation of the vaccine now used for the prevention of typhoid fever.

Its adoption in the United States Army has been attended with brilliant results, as indicated by the table below.

\begin{tabular}{|c|c|c|c|c|c|}
\hline \multirow{2}{*}{ Year } & \multirow{2}{*}{ Vaccination } & \multicolumn{2}{|c|}{ Cases of Typhoid } & \multicolumn{2}{|c|}{ Typhoid Deaths } \\
\hline & & Number & $\begin{array}{c}\text { Rate per } \\
1,000\end{array}$ & Number & $\begin{array}{c}\text { Rate per } \\
1,000\end{array}$ \\
\hline 1907 & None...... & 237 & 3.79 & 19 & .30 \\
\hline 1908 & None..... & 239 & 3.20 & 24 & .31 \\
\hline 1909 & Voluntary... & 282 & 3.35 & 22 & .26 \\
\hline 1910 & Voluntary... & 198 & 2.43 & 14 & .17 \\
\hline 1911 & Voluntary.......... & 70 & .85 & 8 & .10 \\
\hline 1912 & Compulsory.......... & 27 & .31 & 4 & .04 \\
\hline 1913 & Compulsory......... & 3 & .03 & 0 & .00 \\
\hline
\end{tabular}

Mixed vaccines which will protect against typhoid fever Vaccines in and the two distinct forms of a similar the Allied Armies disease, paratyphoid fever, have been used with striking success in the European armies during the present war. The number of cases of typhoid fever among British troops in France up to November 1, 1916, was 1,684 , of paratyphoid cases, 2,534, and of indefinite related fevers, 353, a total of 4,571. In the South African War nearly 60,000 cases of typhoid fever alone were admitted into hospital, and there were 8,227 deaths.

Armies in the past have been an important agent in spreading typhoid and other infections through the regions where they operated and in the homes to which they returned. Today the success of typhoid vaccination in our military establishments points the way to the elimination of this 
disease in civil life. Every man and woman under 45 should make use of this simple and efficient safeguard.

Another method of controlling immunity is by the use of antitoxins, or antitoxic sera, as they are often called, of which diphtheria antitoxin is the best example.

The Use of Antitoxic Sera

Diphtheria antitoxin was introduced into the United States by the New York City Department of Health in 1894, and it has reduced the death rate from diphtheria in that city from 155 deaths for every hundred thousand of the population, to 24. The antitoxin is of comparatively little value when the attack has gone on for a long while and the body has become severely poisoned, but if it is used as soon as the disease begins, it is a practically certain cure.

Antitoxic sera are also used in the treatment of tetanus, meningitis and more recently in certain forms of pneumonia.

From a military standpoint some of the most important applications of the principles of vaccine and serum therapy are those which have been worked out in connection with the treatment of wound infections. The surgeon in

Control of Wound Infections his operating room relies on antiseptic and aseptic methods to keep out the germs of suppuration. Wounds received in battle are generally already infected and the destruction of germ life is impossible without serious injury to the tissues themselves. The military surgeon must therefore rely largely on the stimulation of the defensive machinery of the body (except in the case of tetanus, for which a specific and powerful antitoxin is at his disposal). The newer solutions used in the treatment of wounds, such as Dakin's chloramine, are specially adapted to check bacterial growth without harming the soldier cells of the blood; and the use of a strong salt solution for the treatment of an infected wound produces an increased flow of lymph from the tissues into the wound, thus relieving the inflamed tissues of congestion and setting up a flow of fluid from within outwards, which tends 
to wash away bacteria. Both the lymph and the strong salt solution are unfavorable to the growth of bacteria. So far as the white corpuscles are concerned, strong saline solutions are unfavorable to their vitality; but when the wound has become healthier, it is usual to decrease the strength of the salt solution until its saturation has reached that of a fluid of the same specific gravity as the blood. In a fluid of this degree of concentration the body cells can live and act freely.

\section{TUBERCULOSIS}

Tuberculosis, a disease which causes about one-third of The Great all the deaths which occur between the White Plague ages of 18 and 45, and kills each year about 150,000 people in the United States, is caused by a bacterium which may grow in a great many different parts of the body, although it is most likely to be found in the lungs, causing tuberculosis of the lungs, or consumption. The germ does not grow all through the lungs in this disease, but here and there at special points, where there form hard little knots or tubercles, from which the disease is named.

Tuberculosis of the bones is not uncommon among children, and a great many of the lame people we see on the streets are crippled from this cause.

The primary cause of tuberculosis is a germ discharged in The Germ of Tuberculosis the spray and sputum coughed out by consumptives, and infection comes in most cases from getting these human discharges into the mouth. Sometimes the germ is inhaled in dust, but it is more frequently transferred from one person to another by rather direct contact.

A great many cattle suffer from tuberculosis, and children may become infected by drinking the milk of tuberculous cows. 
To prevent the spread of tuberculosis it is necessary first of all to destroy the germs discharged from the mouths of consumptives; and second, to pasteurize the milk of all cows not certainly known to be free 'from the disease.

How to Prevent the Spread of Tuberculosis Infection

The careless consumptive is a great danger to his family and associates, but one who is always careful to destroy his sputum and to avoid coughing out mouth spray into the air need not be a menace to the health and life of others. The consumptive should always cough into a cloth or handkerchief, or a paper napkin, which can be burned, and all sputum should be received in paper cups and burned at the end of the day. If handkerchiefs are used, they should not be put into a laundry bag or basket with other soiled linen, but should be boiled for twenty minutes in a strong soapsuds solution.

Tuberculosis is a disease in which vital resistance plays a specially important part. The germ is unfortunately very common; in fact, almost every individual, sooner or later, is slightly infected with it.

Vital Resistance against Tuberculosis

This does not mean that every man has tuberculosis, in the sense of suffering from actual disease. The human body has a wonderful power of defending itself against this invader, and a few germs entering a healthy body are quickly overcome. It is when a great many germs are taken in, and particularly when the strength is reduced by attacks of other diseases, or when resistance is lowered by intemperate habits, by living and working in overheated rooms, by eating insufficient food, or by breathing sharp dust particles, that the invisible enemy overcomes the defenses of the body. France has today some 500,000 cases of tuberculosis to care for because of the deadly effects of the strain of trench life upon soldiers who, in a time of crisis, had to be sent to the front whether they were in full physical health or not. 
People who have recovered from tuberculosis, and those in

Dust and

Tuberculosis whose family there has been a case, should be specially on guard against allowing their vital resistance to become weakened. Among the most important causes of tuberculosis are the unsanitary conditions of factory life. An overheated, unventilated workshop is certain to lower vital resistance and make the worker an easy prey to the tuberculosis germ, particularly if he is weakened by long hours of labor. An especially dangerous thing about some industries is the fact that the air of the workshops is full of fine particles of mineral or metallic dust. These dust particles are inhaled and injure the delicate tissues of the lung, so that tuberculosis germs find it easy to grow there. The workers in some of these industries - granite workers and grinders, for instance-are two or three times as likely to contract tuberculosis as are people who work at less dangerous trades.

In all such places there should be special pipes with exhaust fans to draw off the dust from the air. Where this cannot be done, the worker should wear a respirator over his mouth, to keep out the dust particles.

Just as the tuberculosis germ fails to gain a real foothold

The Cure of Tuberculosis in the body of a thoroughly healthy person, so by proper hygienic treatment it can be conquered even after it has begun its work.

There are no medicines, in the ordinary sense, that will cure tuberculosis. All so-called "Consumption Cures" are frauds which take the money of their victims and do them immeasurable harm by wasting precious time. The cure for tuberculosis is hygienic living under the advice of a competent physician, properly directed rest and exercise, plenty of fresh air, and a sufficient amount of wholesome food. If such treatment is taken early in the disease, tuberculosis can generally be cured.

The main thing is to begin the treatment of tuberculosis as soon as possible. The time to put out a fire, or to control 
a disease, is before it gets well under way. When tuberculosis has gone far, it cannot usually be checked, but if the disease is attacked at its beginning, there is every reason to be hopeful. Among the common danger signals are loss of Importance of Early Treatment weight, loss of appetite, prolonged "cold" with cough and spitting-the expectorations sometimes blood-tinged-frequent hoarseness, afternoon fever, chills, nightsweats, easy tiring, and pains in the chest. One of the earliest symptoms of pulmonary tuberculosis is a sense of weakness and loss of energy, both of body and mind, not infrequently out of all proportion to the extent of the disease. If any of these symptoms are present, the patient should go to a physician and have his lungs examined.

\section{RACIAL HEALTH}

Success in the struggle for existence involves

Individual efficiency

Perpetuation of the Race

Both personal health and success in leaving progeny are threatened by the grave communicable maladies which are known as the venereal diseases. Lack of self-control endangers one's life ; it threatens the life of the wife;

The Menace of Venereal Disease it endangers the life of the mother; it imperils the life and the sanity of the child. From the medical standpoint it is vitally important that these diseases should be more fully controlled by public health authorities, that facilities for laboratory diagnosis should be furnished, and that provision should be made for dispensary and hospital treatment. Concealment, delay in securing treatment, and resort to advertising quacks and charlatans are in large measure responsible for the extent of the damage wrought by these infections. 
Around all the camps of England and France the greatThe Enemy of the Soldier and Sailor est enemy of the soldier is the diseased prostitute. Some of the finest British and colonial regiments have been seriously affected. The British government is now taking stern measures to protect its soldiers by the establishment of health zones, and the keeping of the men within certain bounds. In view of the special temptations which will surround our new army in this country and on the continent, the most earnest efforts should be made to control the surroundings of encampments in this regard.

Lieutenant-Colonel Frank R. Keefer, in his text-book on

Opinions of Military Authorities

"Military Hygiene and Sanitation," says: "Venereal infections are responsible for an enormous amount of sickness in the armyvastly more than any other cause-and constitute the most important health problem with which we have to deal." In the "Manual of Military Hygiene," by Colonel Valery Havard, the author points out that on account of the importance of this question, "soldiers should be taught all knowledge deemed necessary and useful on the subject. For instance, that sexual intercourse is not necessary for the attainment of the best physical and mental health, and that a strong, manly character is developed only by self-control and continence. They should have a proper appreciation of the prevalence and gravity of venereal diseases.

"Many men expose themselves thoughtlessly, with the impression that, at the worst, a few days in hospital will suffice to get rid of the consequences. This is foolish and dangerous ignorance which officers, especially medical officers, should endeavor to dispel by a few plain talks, demonstrating to them the many complications and sequels of gonorrhea as well as the ravages of syphilis, which affect not only the incontinent, but, through matrimony, many 
innocent women and children. Let them know that, in the opinion of gynecologists, a majority of the hazardous surgical operations performed upon married women are made necessary in consequence of gonorrheal infection by the husband; and another terrifying fact, that syphilis, so far as absolutely known, is not only directly transmitted from father to children, but the sole disease thus transmitted, as it were, a special curse upon the human race."

More recent studies have shown that the proportion of prostitutes afflicted with venereal disease is far higher than has been assumed by earlier writers. Dr. Walker in an investigation in Baltimore found over 90 per cent. of a group of prostitutes suffering from syphilis alone.

The good soldier owes to his country today his full measure of strength and vigor. He owes to his country of the future a full measure of strength and vitality to be handed on to coming generations. Both may be fatally jeopardized by a moment of weak self-indulgence.

\section{ACCIDENTS AND FIRST AID}

Slight cuts and scratches should be washed free from dirt, then carefully dried and painted with a little tincture of iodine. More serious wounds should be dressed temporarily, until

Cuts and the doctor can attend to them, by covering them with surgeons' gauze fastened on with a bandage. A deep wound, particularly if produced by a rusty nail or other dirty object, should always receive prompt medical attention; so should even the slightest scratch, if, after a few days, it is red, hot or painful. Any wound will heal without much pain or redness if there are no germs in it. Remember that germs get into a wound, not from the air, but from dirty things that touch it. A scratch or cut should never be touched with anything but sterilized surgeons' gauze. In connec- 
tion with automobile accidents, it is well to remember that gasoline is a good disinfectant.

If the blood comes from a wound in jets or spurts, an artery is bleeding, and the result may be serious if the flow is not checked. Fortunately, at most parts of the body the arteries are deeply buried in the flesh. A severed artery calls for prompt action. Put firm pressure close to the bleeding part, between the wound and the heart. In case the wound is in the arm or the leg, the pressure is best applied by tying a knot in the center of a folded handkerchief, and laying this knot over the artery. Tie it loosely around the limb, but with a good knot. Place a stick under the bandage and twist it round and round until the bandage is tight enough to stop the bleeding.

The pain and swelling of an ordinary bruise will be much

Bruises and Sprains less if something cold is placed on the bruise at once to drive the blood away. Ice in a cloth may be used for this purpose, or simply

a cloth wrung out in cold water.

If a joint has been sprained (which means that the ligaments that hold the bones together have been strained or torn), the same treatment with cold cloths is very useful, and should be kept up at intervals for twelve hours. In old and enfeebled patients, hot wet cloths are better. The injured part should be placed as high as possible, so as to keep the blood out of it.

If a bone is broken, medical care is, of course, necessary. Broken

While waiting for the doctor, the only thing Bones to do is to keep the broken limb in as comfortable a position as possible. Above all, do not let the limb bend at the place where the bone is broken, because that gets the splinters of bone out of place, and may drive them through the skin and lead to an infected wound. If you find it necessary to lift a broken limb, put one hand on each side of the break and lift it with both hands at the same time. 
A person who has become faint and dizzy from the direct effect of strong sunlight shining on the head should be placed in a seated position in the shade. His clothing should be loosened, and cold water poured on his head, or

Sunstroke and Heat Prostration his body rubbed with bits of ice. Cool drinks should be given, if possible.

Heat prostration due to excessive heat acting on the whole body, and not to the direct sun's rays, should be treated somewhat differently. The patient should be laid flat on his back in a cool place, his clothing loosened, and his hands and feet rubbed, to restore the circulation. The face and body should be bathed in warm water and warm drinks should be given.

If the clothing catches fire, there is only one thing to do, and it must be done quickly: smother the flame. Fire needs plenty of oxygen, and if a person whose clothing is on fire is quickly and closely wrapped in a coat, shawl, blanket, or rug, the fire will go out.

Burning

Clothing and Treatment of Burns

It is important to remember to wrap the cloth from above down. If the wrapping is done from below, the flames may be driven up and inhaled into the lungs with very serious results. If your clothing catches fire when you are alone, do not run for help, but lie down flat and roll over and over on the floor or on the ground, to smother the flames.

In the case of a slight burn which only reddens the skin without forming a blister, the pain will be lessened if the air is kept from the burned place. A paste of ordinary baking soda and water applied to the burn will do this, or carbolized vaseline, or any grease, like lard, may be used instead. The burn should then be covered by tying a piece of cloth or bandage around it. If there is extensive blistering, the application of soda or vaseline may do harm; and severe burns should be treated like open wounds. 
If ears, nose, or fingers are frost-bitten, the affected part Frost-bite should be rubbed with snow or very cold water until the blood has come back and the flesh begins to sting and burn. On no account should the person go into a warm room until this has been done, and until the frozen part has become gradually warm by rubbing. Even after the circulation has come back, the patient should become warm only gradually.

When a person has been under the water or in some suffoDrowning and cating gas for a long time, the breathing Suffocation stops, and the patient becomes unconscious. If breathing can somehow be started again, recovery may follow. The starting of the breathing movements in a person who has ceased to make them for himself is called artificial respiration.

Artificial respiration should be begun by laying the patient face downward upon the ground. The feet should be raised to drain out any excess water. Stretch the arms of the patient straight above his head and let them rest on the ground in that position. Turn his head a little to one side, so that the air will not be impeded in entering the nose and mouth. Next stand astride of the patient, with your body directly over his hips and facing his head. Put your hands on each side of his back, below the shoulder blades. Your hands now rest upon the patient's lower ribs. The fingers are spread out, pointed toward the head and away from the spine.

Swing your body forward, keeping your arms straight and allowing your weight to rest on the patient's back; then swing back, taking all your weight off the patient. Do this fourteen or sixteen times per minute. This imitates the motions of breathing. When you put your weight on the patient, you press his chest together and force the air from the lungs; when you release the pressure, the chest springs back into place, and the lungs expand and draw air into them. 
Recovery may be very slow; keep up your work for at least two hours.

While this process is going on, some one should remove the patient's clothing. If necessary, he should be dried with a towel and then covered with a blanket. This work must not interfere with the operator who is causing artificial respiration. Compel bystanders to stand back. The patient needs every bit of air he can get.

When the patient begins to breathe,--but not before,- - he should have his legs and arms rubbed toward the body. This should be done without removing the blanket. The patient will not breathe well all at once, and it will be necessary to help him at first by continuing the artificial respiration every little while. Of course, if he stops breathing at any time, the artificial respiration must be renewed.

After he is breathing well, put him to bed. Surround him with hot water-bottles and cover him up well. As soon as he can swallow, give him some hot coffee. Open the windows wide, and allow him to sleep quietly.

Cases of electric shock (from contact with live wires, for example) and cases of gas poisoning require the same treatment-artificial respiration.

If some poisonous drug has been taken, the first thing to do is usually to get it out of the body again as quickly as possible by causing vomiting.

Poisons This may be done by running the finger down the throat, by drinking a large quancity of warm water, or by taking some substance which will cause vomiting, called an emetic. A teaspoonful of mustard or salt in a glass of lukewarm water will serve as an emetic. Promptness is more important than an exact dose. After the emetic has been taken, large quantities of warm water should be drunk, to dilute the poison that remains. 



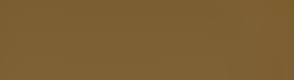




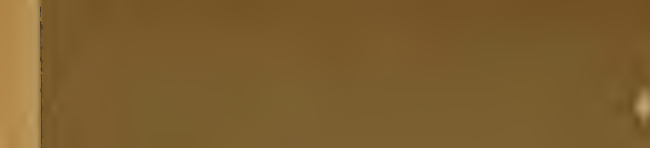

I 


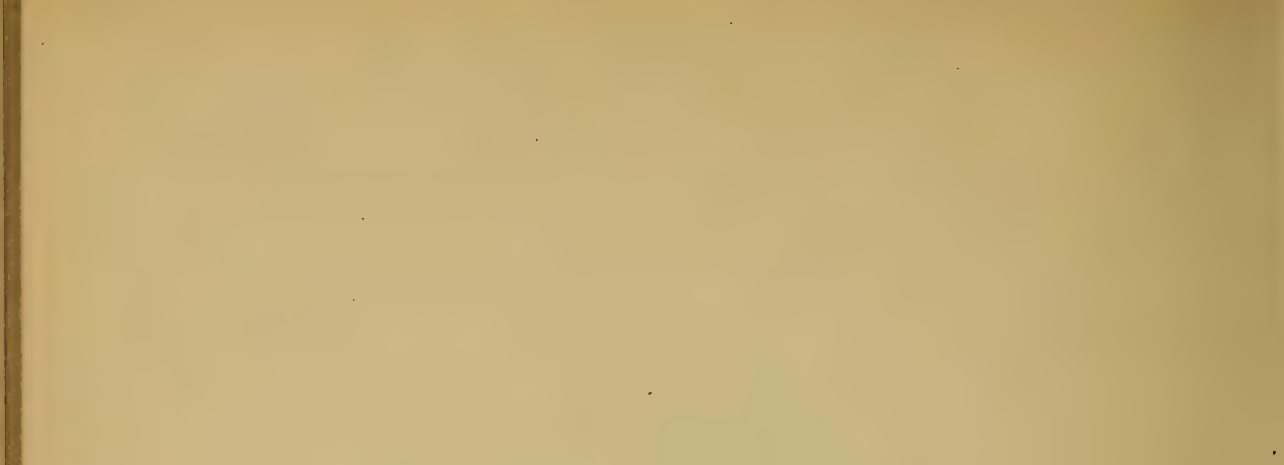




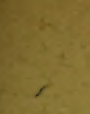





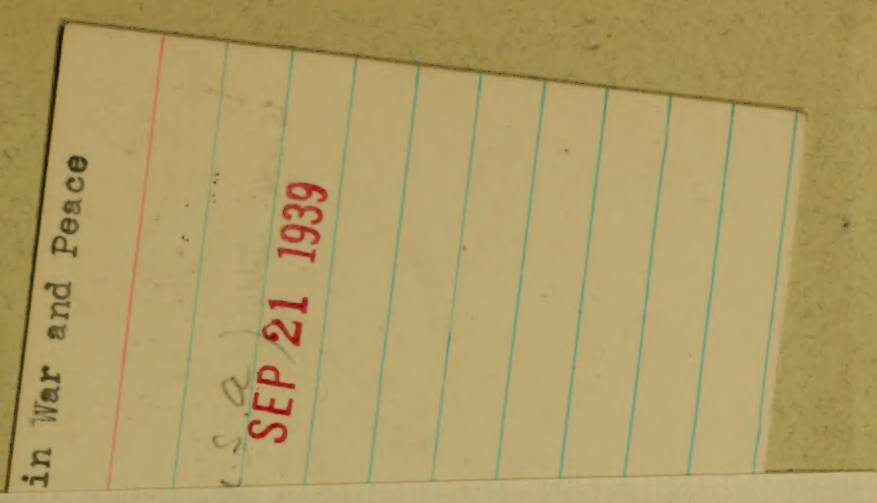


